\title{
Type 1 interferons and myositis
}

\author{
Steven A Greenberg*
}

\begin{abstract}
Recent studies suggest a mechanistic role for molecules induced by type 1 interferons in the pathogenesis of some forms of myositis. For dermatomyositis, evidence that these molecules injure myofibers seems especially strong. In the group of disorders known as polymyositis, the study of blood samples suggests a potential role. It is unknown what drives the sustained presence of type 1 interferoninducible molecules in these diseases, as the type 1 interferons themselves have not been specifically detected along with their downstream biomarkers. Therapeutic development for blockade of IFNa is in progress aided by the identification of blood genomic biomarkers.
\end{abstract}

\section{Introduction}

The inflammatory myopathies - including dermatomyositis (DM), inclusion body myositis, and polymyositis (PM) - are poorly understood autoimmune diseases affecting skeletal muscle. Evidence regarding the significance of type 1 interferons to these diseases, especially $\mathrm{DM}$, is reviewed in the present article, with much of this material recently discussed elsewhere $[1,2]$.

The type 1 interferons are a class of molecules that include IFN $\alpha$ and IFN $\beta$. After binding to the type 1 interferon receptor (IFNAR) on target cells, these cytokines can stimulate the transcription of a set of genes, the type 1 interferon-inducible genes. Proteins abundantly produced from these genes' transcripts - such as myxovirus resistance protein A, interferon-stimulated gene 15 (ISG15), and $2^{\prime}, 5^{\prime}$-oligoadenylate synthetase 1 - remain inside cells. They normally function as defenses against viral infections through a variety of means, such as inhibiting viral transcription, translation, or assembly of viral nucleocapsids. It is possible that the chronic intracellular overproduction of these transcripts and proteins might

*Correspondence: sagreenberg@partners.org

Department of Neurology, Division of Neuromuscular Disease, Brigham and Women's Hospital, 75 Francis Street, Boston, MA 02115, USA be directly harmful to cells, such as muscle fibers in myositis [3].

\section{Myositis, pathology, and mechanisms}

The varied forms of myositis have distinct clinical and pathological features (Figure 1), and probably involve distinct mechanisms of tissue injury. DM, in addition to clinical skin involvement, has two unique pathological features (perifascicular atrophy and endothelial cell tubuloreticular inclusions) that distinguish it from other muscle diseases. Inclusion body myositis has a unique clinical distribution of involvement, with substantial weakness of the quadriceps and wrist and finger flexors, as well as specific suggestive pathological features including rimmed vacuoles. The broad category of PM is mainly distinguished by a collection of otherwise individually nonspecific features. Although frequently lumped together, DM and PM probably involve entirely different mechanisms of tissue injury.

Because type 1 interferons may have many effects on cells of the immune system, they may have roles in the varied immune responses present across multiple myositis subtypes. Yet studies to date suggest that only in DM are these molecules strongly and directly influencing molecular events in muscle.

\section{Why focus on type 1 interferons in dermatomyositis mechanism?}

Recognition that cytokines are present in myositis muscle biopsy samples began with immunohistochemical studies for cytokine proteins [4]. This approach is confounded by a number of technical and biological limitations [5], including nonspecific immunoreactivity, transient expression of cytokines, and their low concentration. For these reasons, some investigators turned to examining cytokine mRNA transcripts in muscle homogenates [6]. Initial PCR-based studies of cytokine transcripts including IFN $\alpha$ and IFN $\gamma$ generally found no myositis subtype-specific differences compared with nonmyositis muscle - except for granulocyte-macrophage colonystimulating factor, which was detected in 12 out of 15 myositis samples but in none out of 10 controls [6]. Many subsequent studies of cytokine transcripts and proteins (discussed in [7-9]) have reported variable and often conflicting results. 


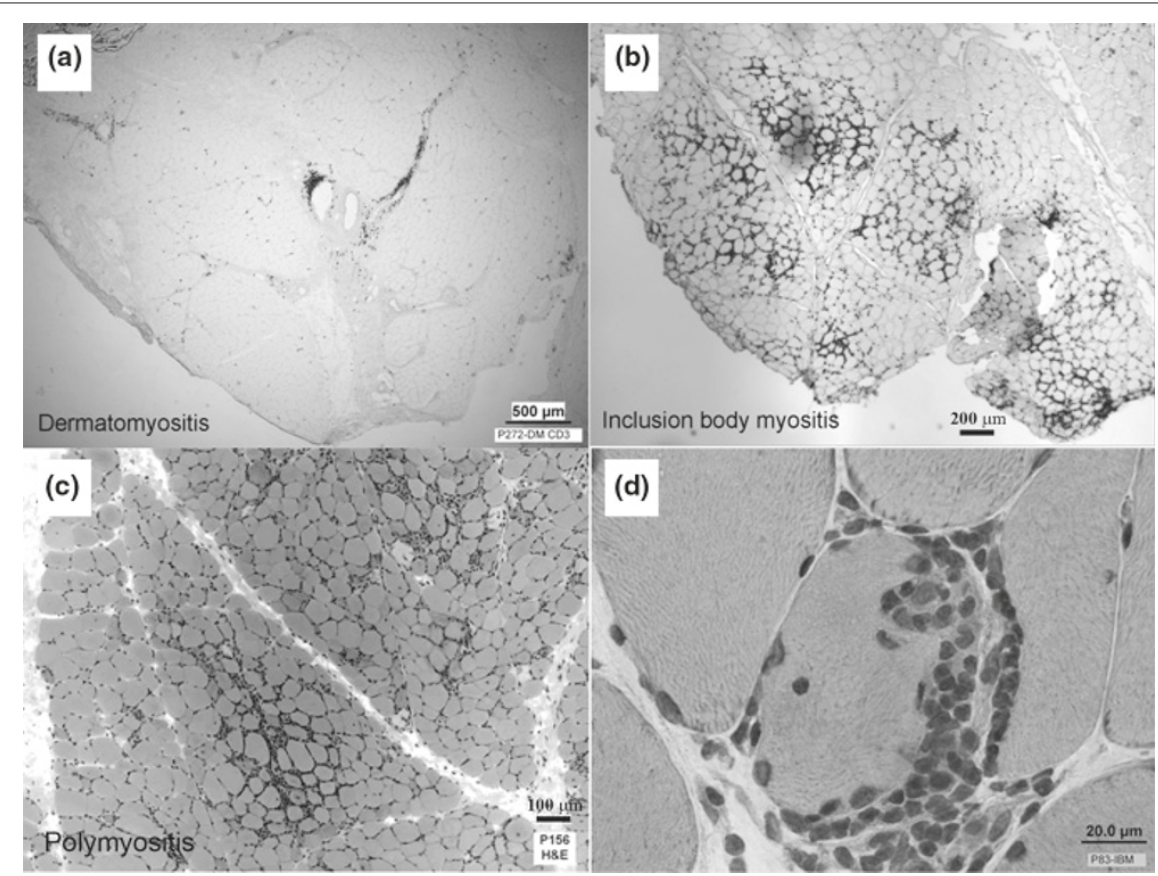

Figure 1. Differing pathologies in myositis subtypes. The distribution of immune system cells differs among myositis subtypes. (a) In dermatomyositis, immune system cells are predominantly in the regions of connective tissue that lie between muscle fascicles and include medium-sized and large blood vessels. In (b) inclusion body myositis and (c) polymyositis, immune cells surround myofibers. (d) Especially in inclusion body myositis, these may sometimes invade myofibers.

Because of the potential for transient expression and the low concentration of cytokines, downstream persisting effects of cytokines have been sought. Two types of biomarkers (macromolecular and molecular) provide strong evidence that DM muscle has experienced strong signaling of the type 1 interferon receptor. More than 25 years ago, tubuloreticular inclusions (also known as lupus inclusions) - macromolecular structures commonly visible with electron microscopy in DM muscle endothelial cells $[10,11]$ and rarely seen in other forms of myositis - were recognized as downstream markers of type 1 interferon signaling. Tubuloreticular inclusions in circulating blood cells develop in patients treated with IFN $\alpha[12,13]$ and those in cultured endothelial cells and other cells develop directly in response to IFN $\alpha$ and IFN $\beta$ [14-16], but not IFN $\gamma$ [13]. For uncertain reasons, no PubMed indexed publication made a connection between this tubuloreticular inclusion literature and DM over 20 years [17].

Over the past 8 years the marked overproduction of type 1 interferon-inducible transcripts and proteins in muscle has been found to be remarkably unique to DM in comparison with all other muscle diseases studied $[2,18,19]$. Microarray gene expression studies of muscle biopsy specimens measuring approximately 18,000 transcripts in each of 113 muscle biopsy samples from patients with a wide range of myopathies showed that only DM samples with perifascicular atrophy have marked elevation of type 1 interferon-inducible transcripts (Figure 2a) [2]. In analyses combining publicly available data, the remarkable specificity of these transcript abundances for DM is impressive. For example, the transcript for the type 1 interferon-inducible gene ISG15 was higher in muscle in all 28 biopsies from adults with DM and perifascicular atrophy and from children with juvenile DM than in every one of 199 non-DM biopsy samples from a wide range of neuromuscular diseases (Figure $2 b$ ).

Two type 1 interferon-inducible proteins have similarly been shown to be highly specific biomarkers of DM muscle. Myxovirus resistance protein A is impressively and uniquely (in comparison with other muscle diseases) abundant in DM myofibers with perifascicular atrophy and in DM capillaries (Figure 3) [18]. ISG15, a ubiquitinlike modifier, is furthermore attached to many other proteins in DM muscle, the identities of which have not been determined (Figure 2c). Exposure of human skeletal muscle cell cultures to IFN $\alpha$ or IFN $\beta$ produces a similar picture of ISG15 conjugation present in human DM samples (Figure 2c) [2].

DM is a systemic disease, involving muscle, skin, and, variably, other tissues. Skin gene expression profiling, reported only in abstract format to date [20], has similarly shown marked abundance of type 1 interferon-inducible transcripts. The topology of keratinocyte injury in DM skin is similar to that of myofiber injury in DM muscle [21]. 


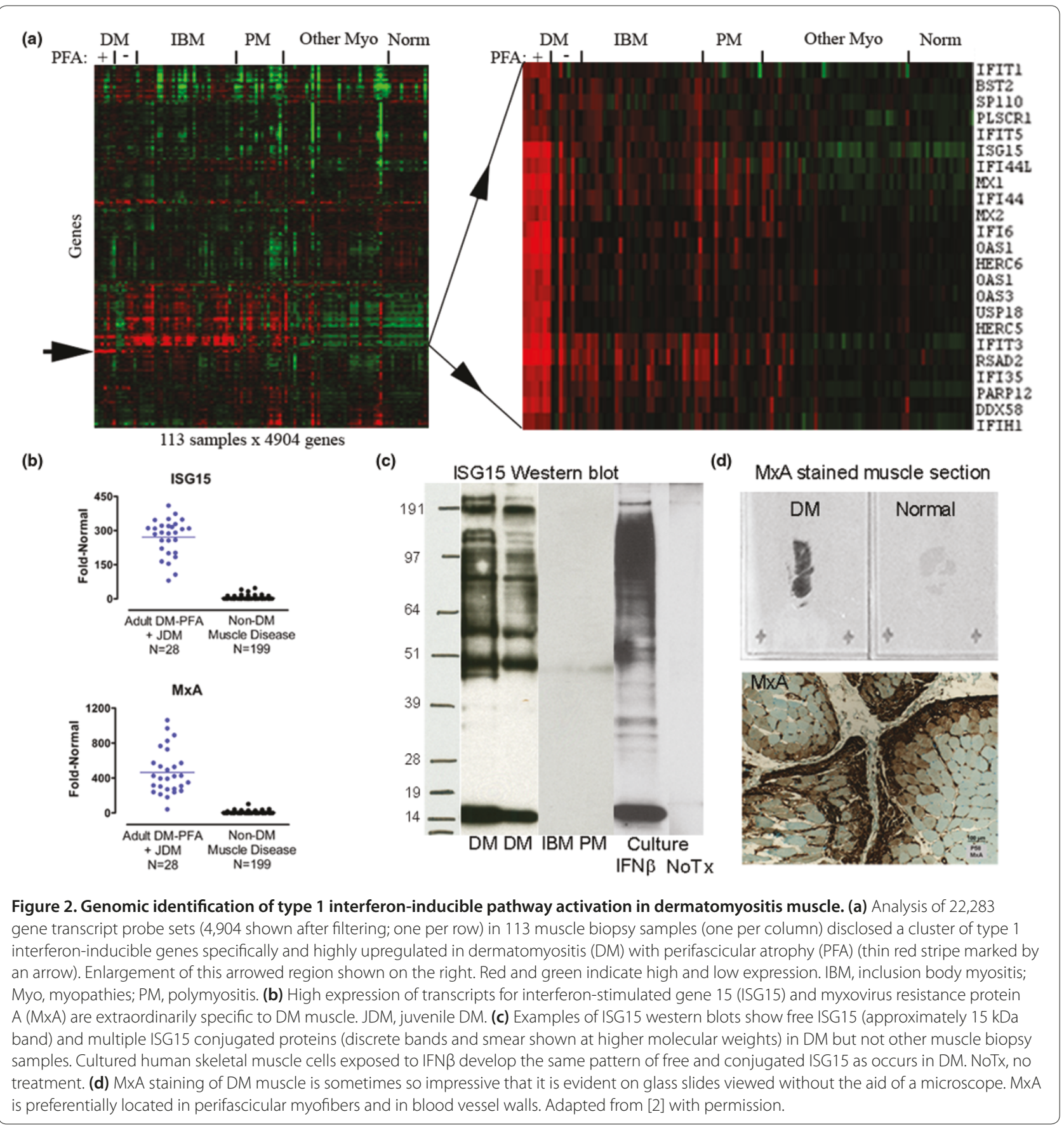

Patients with dermatological features of DM who lack significant clinical evidence of muscle involvement have been classified as clinically amyopathic DM. Autoantibodies to a classic type 1 interferon-inducible protein IFIH1 (interferon induced with helicase $\mathrm{C}$ domain; also called MDA-5) have been recently identified [22]. Using optimized cutoff values in an ELISA assay, the presence of anti-IFIH1 antibodies in clinically amyopathic DM among 262 patients with a range of connective tissue diseases was $69 \%$ sensitive and $99.6 \%$ specific. Significant
anti-IFIH1 autoantibody levels were present in 22 out of 32 patients with clinically amyopathic DM, but only in one of 35 patients with classic DM and in none of 53 patients with PM. These remarkably strong data both indicate a clinically valuable biomarker of clinically amyopathic DM and provide mechanistic evidence for some abnormality related to type 1 interferons in clinically amyopathic DM. The nature of this relationship is uncertain; one speculation is that IFIH1, a nuclear RNA helicase, is overproduced or altered in some way in 


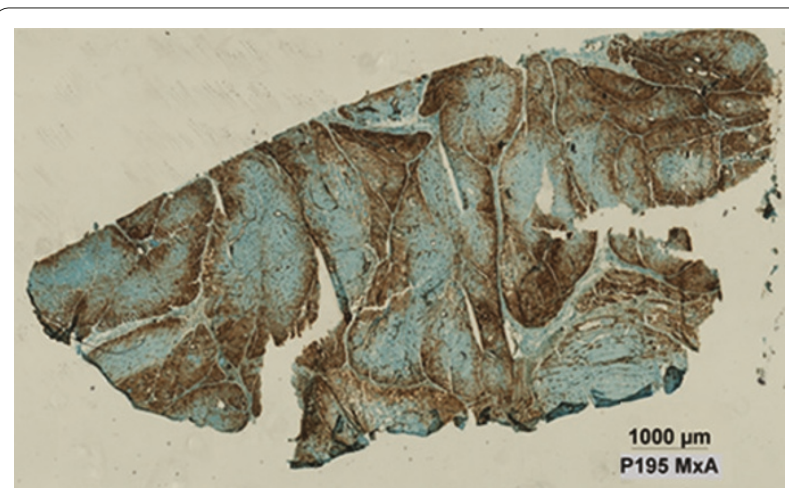

Figure 3. Myxovirus resistance protein A expression in dermatomyositis muscle. Image of whole muscle section stained for myxovirus resistance protein A (MXA) showing abundant myofiber protein expression (brown) preferentially in a perifascicular distribution. Adapted from [3] with permission.

clinically amyopathic DM, and evokes an autoantibody response.

\section{A blood type 1 interferon-inducible signature}

Blood gene expression profiling has also demonstrated marked abundance of these transcripts in patients with active DM, such as untreated patients, but also in PM (see below) [19]. One study that did not find marked type 1 interferon-inducible transcript abundance in DM blood samples had included almost only treated patients (11 out of 12 patients receiving prednisone; eight of these patients receiving an additional second immunosuppressant agent) [23]. Microarray experiments measure the abundance of 10,000 s of transcripts simultaneously; any set of transcripts may be called a signature, but what is impressive about such experiments in DM and PM blood samples is the dominance of these gene expression patterns by type 1 interferon-inducible genes. In a study of 23 patients with DM and PM, at least 24 of the highest expressed 25 genes among approximately 38,000 genes studied are all known to be highly inducible by type 1 interferons [19].

The type 1 interferon-inducible transcript overproduction in DM and PM is highly correlated, within individual patients, with clinical measures of disease activity [19] (Figure 4 and unpublished data). Although the absolute magnitude of the upregulation of this signature does not highly correlate with disease severity across patients, within individual patients the signature does track disease activity - a situation similar to the commonly used clinical biomarker creatine kinase.

\section{What drives the production of these downstream biomarkers of type 1 interferon signaling in DM muscle?}

A fundamental question that has not been answered is what drives the production of type 1 interferon-inducible molecules in DM muscle. Specific elevation of type 1 interferon transcripts or proteins has not been demonstrated in DM muscle. Both microarray and real-time quantitative PCR do not show impressive differences, compared with other myositis samples, in transcripts encoding a range of IFN $\alpha$ subtypes or IFN $\beta$ in the same DM muscle samples that have marked upregulation (10-fold to 100-fold) of downstream type 1 interferoninducible transcripts (unpublished data). Immunoblots from myositis samples similarly do not appear to show differential presence of IFN $\alpha$ or IFN $\beta$ protein in DM muscle (preliminary unpublished data).

This situation parallels that seen in systemic lupus erythematosus. Although studies performed almost 30 years ago detected molecules believed to be IFN $\alpha$ in 60 to $76 \%$ of systemic lupus erythematosus blood samples using functional antiviral assays sometimes in combination with neutralizing antibodies [24-27], the literature has been notable for the absence of detection of IFN $\alpha$ in systemic lupus erythematosus blood or tissue samples by direct methods such as ELISA, immunoblot, or mass spectrometry. For example, one study found measurable levels of IFN $\alpha$ protein by ELISA in only two out of 38 patients, while most of these same 38 samples showed marked increases in type 1 interferon-inducible transcripts [28]. The lack of direct detection of IFN $\alpha$ protein has been attributed to potential technical limitations, although unexpected results in science have often been assumed to be erroneous. A more recent functional assay looking at type 1 interferon-inducible transcription has similarly detected activity in systemic lupus erythematosus plasma [29].

The interpretation of the results of functional assays is complicated by potential type 1 interferon autocrine mechanisms. In mouse cells, autostimulation of the IFNAR by early secreted type 1 interferons results in marked amplification of IFN $\alpha$ production [30-33]. AntiIFN $\alpha$ antibodies used in functional assays to neutralize sample IFN $\alpha$ could potentially diminish type 1 interferoninducible gene transcription through neutralizing early secreted reporter cell IFN $\alpha$, although this possibility is speculative.

For juvenile DM, the functional assay for gene transcription has been used for detection of serum type 1 interferon-inducing activity and similarly interpreted as indicating the presence of IFN $\alpha$ in some blood samples [34]. What is particularly remarkable about this study was the marked range of interferon-inducing activity of serum from healthy children and adults, which varies by over 100-fold and includes many healthy people whose activity exceeded the mean value for the juvenile DM population.

These data suggest that the marked production of type 1 interferon-inducible transcripts and proteins in 

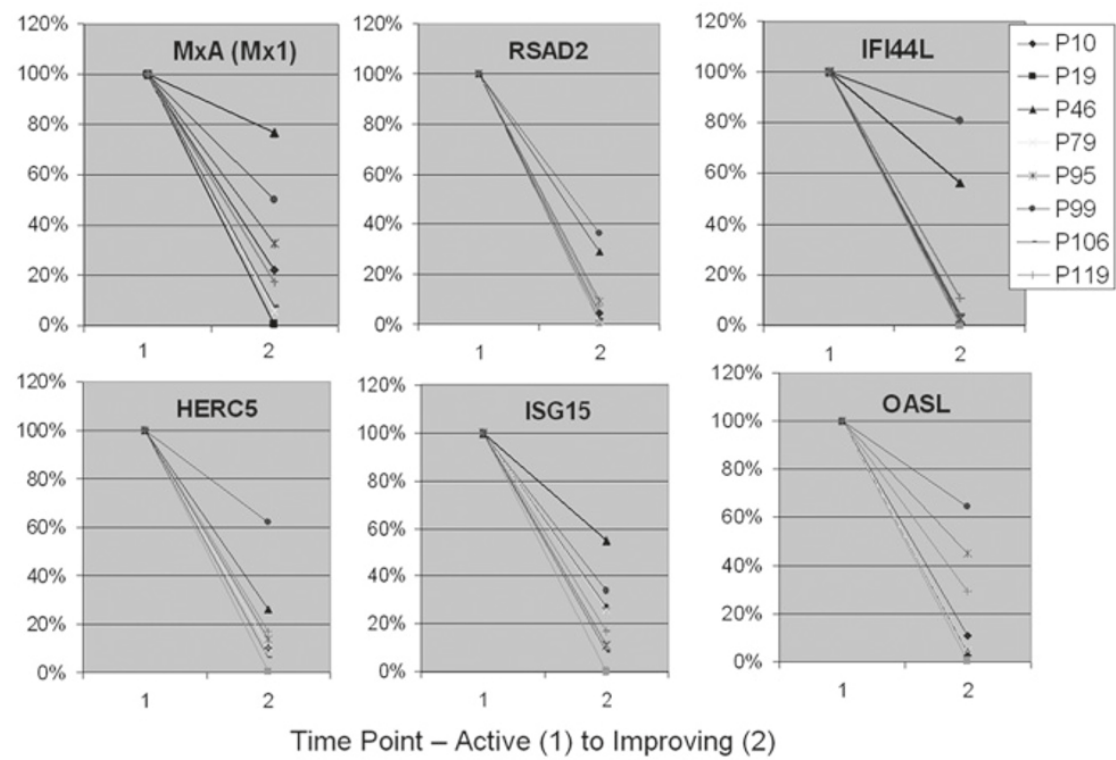

Figure 4. Blood type 1 interferon-inducible gene expression correlation with disease activity. Downregulation of six type 1 interferoninducible genes in eight patients, correlating with improvement in clinical disease from time point 1 (active) to time point 2 (improving). Adapted from [19] with permission.

DM muscle, probably by myofibers, might result from sustained activation of the type 1 interferon receptor IFNAR in the absence of excessive (compared with the wide range of normal) type 1 interferons, or through mechanisms even further downstream that bypass IFNAR. The most natural interpretation of the data to date suggests that what may turn out to be most crucial with regard to DM myofiber injury is not the abundance of a type 1 interferon, but rather sustained abnormal function of the IFNAR or a further downstream process.

\section{Potential role for type 1 interferons in polymyositis and inclusion body myositis}

PM is an umbrella term for patients with various forms of myositis that are difficult to classify. DM and PM have substantial differences with regard to abundance of type 1 interferon-inducible molecules in muscle biopsy samples (Figure 5), yet marked overexpression of type 1 interferon-inducible genes has also been found in blood in PM [19]. Within PM muscle, inflammatory cells typically surround, displace, and sometimes invade muscle fibers. These cells include T cells, myeloid dendritic cells, macrophages, and plasma cells (reviewed in [3]). Type 1 interferons have multiple effects on these cell types, and it is possible that through these effects the type 1 interferon system is contributing to PM myofiber injury.

Patients with inclusion body myositis - a highly inflammatory disorder of muscle, as judged by abundance of immune system cells and transcripts in muscle - do not have high levels of muscle or blood type 1 interferon-inducible transcripts (Figure 5), although a small proportion of patients may have modest elevation of such transcripts in blood alone. As in PM, the mechanistic interpretation of blood expression of these transcripts is uncertain, and could reflect less-specific effects driving immune cell development.

\section{Predicted exacerbations with TNFa inhibition}

TNF $\alpha$ appears to have an antagonistic relationship with type 1 interferons [35]. It may directly inhibit the generation of plasmacytoid dendritic cells from progenitor cells and may inhibit plasmacytoid dendritic cell production of type 1 interferons. Studies of etanercept in Sjogren's syndrome indeed showed that this drug increased type 1 interferon activity [36]. Accordingly, models that propose a significant role for type 1 interferons in the pathogenesis of myositis predict that TNF $\alpha$ inhibition might exacerbate myositis. Published experience with TNF $\alpha$ inhibition in patients with myositis appears to support this model. Two open-label studies of infliximab have been terminated before completion or had substantial dropout rates for reasons that included disease progression [37,38]. Although this class of drugs may prove useful in the management of some patients, currently it appears unlikely to be of more general use for myositis.

\section{Conclusion: diagnostics and therapeutic development}

The presence of marked overproduction of type 1 interferon-inducible transcripts in blood specimens from 


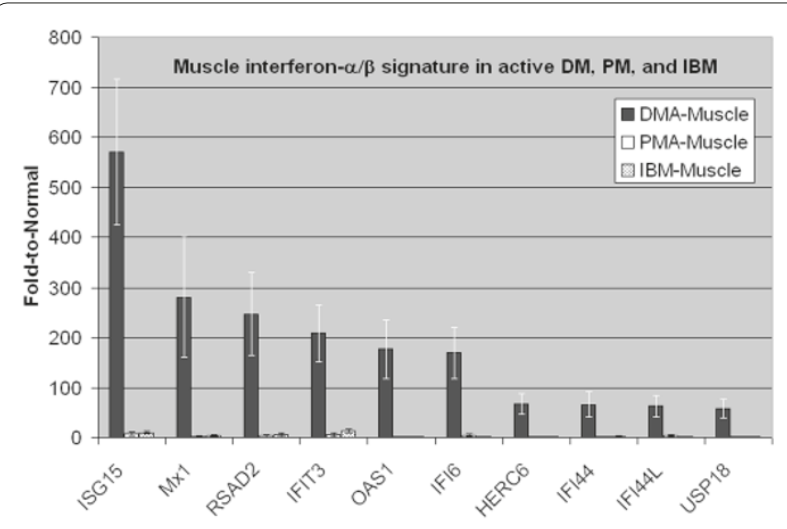

Figure 5. Distinct muscle expression of type 1 interferoninducible genes in inflammatory myopathies. Distinct muscle expression of type 1 interferon-inducible genes in dermatomyositis (DM) compared with polymyositis (PM) and inclusion body myositis (IBM). Muscle microarray data shown for 20 patients (five each with active dermatomyositis (DMA), active polymyositis (PMA), untreated IBM, and normal) with plotted mean values and error bars for mean \pm standard error for each group. Highly expressed genes in DM muscle are orders of magnitude greater than in PM and IBM. Adapted from [19] with permission.

patients with active DM and PM has potential for diagnostic use [19]. These biomarkers may be able to distinguish these disorders from inclusion body myositis and other muscle diseases that sometimes present diagnostic uncertainty. Furthermore, they may be useful for therapeutic development. A phase $1 \mathrm{~b}$ trial of anti-IFN $\alpha$ therapy has been initiated in DM and PM [39]. Entry criteria into this study include the presence of sufficiently high type 1 interferon-inducible gene expression in blood. Future studies targeting the IFNAR or further downstream events have strong rationale in DM, and perhaps in PM.

\section{Abbreviations}

$\mathrm{DM}=$ dermatomyositis; ELISA = enzyme-linked immunosorbent assay; IFN = interferon; IFNAR = type 1 interferon receptor; ISG15 = interferon-stimulated gene 15; PCR = polymerase chain reaction; $P M=$ polymyositis; $T N F=$ tumor necrosis factor.

\section{Competing interests}

SAG has worked as a consultant regarding clinical trial planning for Medlmmune, LLC and has a Sponsored Research Agreement with MedImmune, LLC. SAG is an inventor of intellectual property pertaining to myositis diagnostics. SAG has National Institutes of Health funding and the publication of articles constitutes evidence of productivity that may be used to support future requests for National Institutes of Health funding.

\section{Acknowledgements}

The present work was supported by grants to SAG from the National Institutes of Health (R01NS43471 and R21NS057225), the Muscular Dystrophy Association (MDA3878), and Medlmmune, LLC.

This article is part of Arthritis Research \& Therapy Volume 12 Supplement 1: The role of IFN alpha in autoimmune disease. The full contents of the supplement are available online at http://arthritis-research.com/supplements/12/S1. Publication of the supplement has been supported with funding from Medlmmune, LLC.
Published: 14 April 2010

\section{References}

1. Greenberg SA: Inflammatory myopathies: disease mechanisms. Curr Opin Neurol 2009, 22:516-523.

2. Salajegheh $M$, Kong SW, Pinkus JL, Walsh RJ, Liao A, Nazareno R, Amato AA, Krastins B, Morehouse C, Higgs BW, Jallal B, Yao Y, Sarracino DA, Parker KC, Greenberg SA: Interferon-stimulated gene 15 (ISG15) conjugates proteins in dermatomyositis muscle with perifascicular atrophy. Ann Neurol 2009, 67:53-63

3. Greenberg SA: Proposed immunologic models of the inflammatory myopathies and potential therapeutic implications. Neurology 2007 , 69:2008-2019.

4. Isenberg DA, Rowe D, Shearer M, Novick D, Beverley PC: Localization of interferons and interleukin 2 in polymyositis and muscular dystrophy. Clin Exp Immunol 1986, 63:450-458.

5. Emslie-Smith AM, Arahata K, Engel AG: Major histocompatibility complex class I antigen expression, immunolocalization of interferon subtypes, and T cell-mediated cytotoxicity in myopathies. Hum Pathol 1989, 20:224-231.

6. Lundberg I, Brengman JM, Engel AG: Analysis of cytokine expression in muscle in inflammatory myopathies, Duchenne dystrophy, and non-weak controls. J Neuroimmunol 1995, 63:9-16.

7. Figarella-Branger D, Civatte M, Bartoli C, Pellissier JF: Cytokines, chemokines, and cell adhesion molecules in inflammatory myopathies. Muscle Nerve 2003, 28:659-682.

8. Salomonsson S, Lundberg IE: Cytokines in idiopathic inflammatory myopathies. Autoimmunity 2006, 39:177-190.

9. Schmidt J, Barthel K, Wrede A, Salajegheh M, Bahr M, Dalakas MC: Interrelation of inflammation and APP in SIBM: IL-1 beta induces accumulation of beta-amyloid in skeletal muscle. Brain 2008, 131(Pt 5):1228-1240.

10. Banker BQ: Dermatomyostis of childhood, ultrastructural alteratious of muscle and intramuscular blood vessels. J Neuropathol Exp Neurol 1975, 34:46-75.

11. Norton WL, Velayos E, Robison L: Endothelial inclusions in dermatomyositis. Ann Rheum Dis 1970, 29:67-72.

12. Grimley PM, Davis GL, Kang YH, Dooley JS, Strohmaier J, Hoofnagle JH: Tubuloreticular inclusions in peripheral blood mononuclear cells related to systemic therapy with alpha-interferon. Lab Invest 1985, 52:638-649.

13. Rich SA, Owens TR, Bartholomew LE, Gutterman JU: Immune interferon does not stimulate formation of alpha and beta interferon induced human lupus-type inclusions. Lancet 1983, 1:127-128.

14. Grimley PM, Rutherford MN, Kang YH, Williams T, Woody JN, Silverman RH: Formation of tubuloreticular inclusions in human lymphoma cells compared to the induction of 2'-5' -oligoadenylate synthetase by leucocyte interferon in dose-effect and kinetic studies. Cancer Res 1984, 44:3480-3488.

15. Kuyama J, Kanayama Y, Mizutani H, Katagiri S, Tamaki T, Yonezawa T, Tarui S, Morise H, Arimura H, Suyama T: Formation of tubuloreticular inclusions in mitogen-stimulated human lymphocyte cultures by endogenous or exogenous alpha-interferon. Ultrastruct Pathol 1986, 10:77-85.

16. Feldman D, Goldstein AL, Cox DC, Grimley PM: Cultured human endothelial cells treated with recombinant leukocyte $A$ interferon. Tubuloreticular inclusion formation, antiproliferative effect, and 2',5' oligoadenylate synthetase induction. Lab Invest 1988, 58:584-589.

17. Greenberg SA, Amato AA: Uncertainties in the pathogenesis of adult dermatomyositis. Curr Opin Neurol 2004, 17:359-364.

18. Greenberg SA, Pinkus JL, Pinkus GS, Burleson T, Sanoudou D, Tawil R, Barohn RJ, Saperstein DS, Briemberg HR, Ericsson M, Park P, Amato AA: Interferonalpha/beta-mediated innate immune mechanisms in dermatomyositis. Ann Neurol 2005, 57:664-678.

19. Walsh RJ, Kong SW, Yao Y, Jallal B, Kiener PA, Pinkus JL, Beggs AH, Amato AA, Greenberg SA: Type I interferon-inducible gene expression in blood is present and reflects disease activity in dermatomyositis and polymyositis. Arthritis Rheum 2007, 56:3784-3792.

20. Kea B, Pesich R, Chung LS, Brown PO, Fiorentino D: Genomic analyses identify lipid metabolism abnormalities in dermatomyositis patients [abstract]. J Invest Dermato/ 2007, 127(Suppl 1):S12.

21. Greenberg SA, Fiorentino D: Similar topology of injury to keratinocytes and myofibres in dermatomyositis skin and muscle. Br J Dermatol 2009, 160:464-465. 
22. Sato S, Hoshino K, Satoh T, Fujita T, Kawakami Y, Fujita T, Kuwana M: RNA helicase encoded by melanoma differentiation-associated gene 5 is a major autoantigen in patients with clinically amyopathic dermatomyositis: association with rapidly progressive interstitial lung disease. Arthritis Rheum 2009, 60:2193-2200.

23. Baechler EC, Bauer JW, Slattery CA, Ortmann WA, Espe KJ, Novitzke J, Ytterberg SR, Gregersen PK, Behrens TW, Reed AM: An interferon signature in the peripheral blood of dermatomyositis patients is associated with disease activity. Mol Med 2007, 13:59-68.

24. Hooks JJ, Jordan GW, Cupps T, Moutsopoulos HM, Fauci AS, Notkins AL: Multiple interferons in the circulation of patients with systemic lupus erythematosus and vasculitis. Arthritis Rheum 1982, 25:396-400

25. Hooks JJ, Moutsopoulos HM, Geis SA, Stahl NI, Decker JL, Notkins AL: Immune interferon in the circulation of patients with autoimmune disease. N Engl J Med 1979, 301:5-8.

26. Preble OT, Black RJ, Friedman RM, Klippel JH, Vilcek J: Systemic lupus erythematosus: presence in human serum of an unusual acid-labile leukocyte interferon. Science 1982, 216:429-431.

27. Ytterberg SR, Schnitzer TJ: Serum interferon levels in patients with systemic lupus erythematosus. Arthritis Rheum 1982, 25:401-406.

28. Baechler EC, Batliwalla FM, Karypis G, Gaffney PM, Ortmann WA, Espe KJ, Shark KB, Grande WJ, Hughes KM, Kapur V, Gregersen PK, Behrens TW: Interferon-inducible gene expression signature in peripheral blood cells of patients with severe lupus. Proc Natl Acad Sci U S A 2003, 100:2610-2615.

29. Hua J, Kirou K, Lee C, Crow MK: Functional assay of type I interferon in systemic lupus erythematosus plasma and association with anti-RNA binding protein autoantibodies. Arthritis Rheum 2006, 54:1906-1916.

30. Sato M, Suemori H, Hata N, Asagiri M, Ogasawara K, Nakao K, Nakaya T, Katsuki M, Noguchi S, Tanaka N, Taniguchi T: Distinct and essential roles of transcription factors IRF-3 and IRF-7 in response to viruses for IFN-alpha/ beta gene induction. Immunity 2000, 13:539-548.

31. Sato M, Tanaka N, Hata N, Oda E, Taniguchi T: Involvement of the IRF family transcription factor IRF-3 in virus-induced activation of the IFN-beta gene. FEBS Lett 1998, 425:112-116.
32. Marie I, Durbin JE, Levy DE: Differential viral induction of distinct interferonalpha genes by positive feedback through interferon regulatory factor-7. Embo J 1998, 17:6660-6669.

33. Sato M, Hata N, Asagiri M, Nakaya T, Taniguchi T, Tanaka N: Positive feedback regulation of type I IFN genes by the IFN-inducible transcription factor IRF-7. FEBS Lett 1998, 441:106-110.

34. Niewold TB, Kariuki SN, Morgan GA, Shrestha S, Pachman LM: Elevated serum interferon-alpha activity in juvenile dermatomyositis: associations with disease activity at diagnosis and after thirty-six months of therapy. Arthritis Rheum 2009, 60:1815-1824

35. Palucka AK, Blanck JP, Bennett L, Pascual V, Banchereau J: Cross-regulation of TNF and IFN-alpha in autoimmune diseases. Proc Natl Acad Sci U S A 2005 102:3372-3377.

36. Mavragani CP, Niewold TB, Moutsopoulos NM, Pillemer SR, Wahl SM, Crow MK: Augmented interferon-alpha pathway activation in patients with Sjogren's syndrome treated with etanercept. Arthritis Rheum 2007, 56:3995-4004.

37. Hengstman GJ, De Bleecker JL, Feist E, Vissing J, Denton CP, Manoussakis MN Slott Jensen $H$, van Engelen BG, van den Hoogen FH: Open-label trial of anti-TNF-alpha in dermato- and polymyositis treated concomitantly with methotrexate. Eur Neurol 2008, 59:159-163.

38. Dastmalchi $M$, Grundtman C, Alexanderson H, Mavragani CP, Einarsdottir H, Helmers SB, Elvin K, Crow MK, Nennesmo I, Lundberg IE: A high incidence of disease flares in an open pilot study of infliximab in patients with refractory inflammatory myopathies. Ann Rheum Dis 2008, 67:1670-1677.

39. A study to evaluate safety of multi-dose MEDI-545 in adult patients with dermatomyositis or polymyositis [http://clinicaltrials.gov/ct2/show/ NCT00533091]

doi:10.1186/ar2885

Cite this article as: Greenberg SA: Type 1 interferons and myositis. Arthritis Research \& Therapy 2010, 12(Suppl 1):S4. 